\title{
Stigma and its Neurological and Psychological Effects in Epilepsy
}

Can. J. Neurol. Sci. 2008; 35: 403-404

Admirably, the article in this issue on Stigma by Bandstra and the Camfields ${ }^{1}$ of the Dalhousie paediatric epilepsy group focuses on this aspect of epilepsy that is every bit as injurious and constraining as the seizures themselves. "Stigma" has been defined as "undesired differentness". 2

Epilepsy is often considered not only a medical disorder but also a social label. ${ }^{3}$ The diagnosis of epilepsy distresses many patients as they recognise epilepsy as a stigmatising condition anchored in perceived negative societal attitudes. Principal generators of stigma include the disruptiveness of seizures in social situations and concealability of the disorder. ${ }^{4}$ The proportion of patients feeling highly stigmatised is significantly greater among patients with uncontrolled seizures than those seizure-free. Fear of consequences of disclosing the condition leads to concealment in a majority of patients, an anxietyproducing situation. ${ }^{4,5}$

The Bandstra et al article thoroughly reviews the several negative implications of stigma for persons with epilepsy. Stigma reduces quality of life, and undoubtedly predisposes the person with epilepsy to psychological comorbidities such as anxiety and depression.-7 Strong family support can reduce stigma, ${ }^{4}$ but families of epilepsy patients are more likely to be dysfunctional than those of patients with other chronic disorders. ${ }^{8}$ Such patients are also more likely to be rejected by society. ${ }^{9}$

Importantly, patients and their families less commonly promote support for their disorder likely because of a lower educational level ${ }^{8}$ and the aforementioned non-disclosure strategy adopted by many. 4

Reflecting the relative capacity of neurological disorders to produce stigma is the number of articles in PubMed on this topic: Epilepsy-164, Parkinson's disease-27, Multiple Sclerosis -12, Stroke - 10, Alzheimer's - 2, ALS - 0. Such proportions likely impact fund-raising efforts.

\section{Reducing Stigma}

Efforts in recent decades to reduce centuries-long negative stereotypes, and to eradicate the stigma of epilepsy, have included not only surveys of public knowledge and attitudes, but also educational programs. The Dalhousie authors evaluate programs designed to reduce stigma, finding many falling short of their goals. Bandstra et al illustrate how, despite dedicated efforts at stigma reduction, misperceptions and negative attitudes persist.

Educating specific groups of persons about stigma appears to be the best strategy. Such persons would be: the patients, their families and close associates; actual or potential employers of persons with epilepsy; and principals and teachers of primary and secondary schools.
Some basis for optimism exists. The Bandstra article reviews and discusses school educational programs, founded on the concept that targeting school-age children can help prevent stigma before it develops. A promising illustration is a Grade 5 education program, now implemented in the Ontario school curriculum, developed by Martiniuk et al. ${ }^{10}$ In a somewhat older population (Canadian college students) Young et $\mathrm{al}^{11}$ developed a questionnaire to reliably examine knowledge and attitudes regarding epilepsy. Following a simple educational intervention (providing a brochure), there was an improvement in knowledge concerning epilepsy, but no corresponding attitudinal change. As Bandstra et al make clear such efforts are positive, but there remains much to be accomplished.

\section{Research Support}

With 15,000 new cases annually in Canada, the incidence of epilepsy exceeds that of colon cancer and almost equals that of breast or prostate cancer. Although epilepsy equals stroke as the most prevalent neurological disorder after headache, its annual research support is less than $30 \%$ of that available for Parkinson's Disease and less than $10 \%$ of funds for multiple sclerosis research. ${ }^{12}$ Stigma likely helps create these disproportionate amounts.

Epilepsy associations thus need to expand the scope of their mandates from only a direct patient support and education function to a political and campaigning role. This enlarged thrust is well exemplified by "Unite Against Epilepsy", a joint campaign of the Canadian League Against Epilepsy and The Canadian Epilepsy Alliance. ${ }^{12}$ This effort will hopefully provide more funds for clinical and basic epilepsy research and care and will reduce stigma, the unwanted additional burden of this treatable disorder.

\section{Conclusion}

We hope this important article by Bandstra and the Camfields will re-focus attention on a vital issue which is easily overlooked in clinical practice, and that it will generate both creative research and vigorous anti-stigma initiatives.

Warren T. Blume, Paul A. Derry London, Ontario 


\section{REFERENCES}

1. Bandstra, NF, Camfield CS, Camfield PR. Stigma of epilepsy. Can J Neurol Sci. 2008;35:436-40.

2. Goffman E. Stigma: notes on the management of spoiled identity. Englewood Cliffs, NJ: Prentice Hall; 1963.

3. Scambler G. Epilepsy. London: Tavistock; 1989.

4. Jacoby A, Austin JK. Social stigma for adults and children with epilepsy. Epilepsia. 2007;48 Suppl 9:6-9.

5. Westbrook LE, Bauman LF, Shinnar S. Applying stigma theory to epilepsy: a test of a conceptual model. J Ped Psychol. 1992;17:633-49.

6. Jacoby A, Baker GA, Steen N, Potts P, Chadwick DW. The clinical course of epilepsy and its psychosocial correlates: findings from a UK community study. Epilepsia. 1996;37:148-61.

7. Hermann B, Seidenberg M, Jones J. The neurobehavioural comorbidities of epilepsy: can a natural history be developed? Lancet Neurol. 2008 Feb;7(2):151-60.
8. Wiebe S, Bellhouse DR, Fallahay C, Eliasziw M. Burden of epilepsy: the Ontario Health Survey. Can J Neurol Sci. 1999;26(4):263-70.

9. Bagley C. Social prejudice and the adjustment of people with epilepsy. Epilepsia. 1972;13:33-45.

10. Martiniuk ALC, Speechley KN, Secco M, Campbell MK, Donner A. Evaluation of an epilepsy education program for Grade 5 students: a cluster randomized trial. Epilepsy Behav. 2007; 10:604-10.

11. Young GB, Derry P, Hutchinson I, John V, Matijevic S, Parrent L, et al. An epilepsy questionnaire study of knowledge and attitudes in Canadian college students. Epilepsia. 2002;43(6): 652-8.

12. Carmant L. Personal Communication, 2008. 